Case Report

\title{
Methimazole Associated Neutropenia in a Preterm Neonate Treated for Hyperthyroidism
}

\author{
Dimitrios Angelis, ${ }^{1,2}$ Rita Ann Kubicky, ${ }^{1}$ and Alan B. Zubrow ${ }^{1}$ \\ ${ }^{1}$ St. Christopher's Hospital for Children, Drexel University College of Medicine, Philadelphia, PA 19134, USA \\ ${ }^{2}$ Division of Neonatology, Department of Pediatrics, Texas Tech University Health Sciences Center, Odessa, TX 79763, USA \\ Correspondence should be addressed to Dimitrios Angelis; dimitrios.angelis@ttuhsc.edu
}

Received 20 November 2014; Revised 13 February 2015; Accepted 13 February 2015

Academic Editor: Suat Simsek

Copyright ( 2015 Dimitrios Angelis et al. This is an open access article distributed under the Creative Commons Attribution License, which permits unrestricted use, distribution, and reproduction in any medium, provided the original work is properly cited.

Maternal Graves' disease is relatively uncommon with an estimated incidence of $0.4 \%-1 \%$ of all pregnancies, but only $1-5 \%$ of newborns delivered to mothers with Graves' disease develop overt clinical signs and symptoms of hyperthyroidism. Here, we describe a case of a 1380-gram female neonate who was born at 30-week gestation to a mother with Graves' disease. Our patient presented with hyperthyroidism followed by transient hypothyroidism requiring treatment with levothyroxine. While hyperthyroid, she was treated with methimazole, iodine, and a beta-blocker. 20 days after the initiation of methimazole, she developed neutropenia. The neutrophil counts started to improve immediately after the initiation of the weaning of methimazole. To the best of our knowledge, this is the first case reported in the literature of methimazole induced neutropenia in a preterm infant being treated for neonatal Graves' disease.

\section{Introduction}

We describe a case of methimazole related neutropenia in a preterm neonate with hyperthyroidism, born to a mother with Graves' disease. The neutropenia was noted 20 days after the initiation of methimazole and improved within 10 days after decreasing the dose of the medication. To the best of our knowledge, this is the first case reported in the literature of methimazole induced neutropenia in a preterm infant being treated for neonatal Graves' disease.

\section{Case Report}

A 1380-gram female neonate was born at 30-week gestation to a G1P0 mother with hyperthyroidism from Graves' disease; she was first diagnosed one year earlier and was started on methimazole 4 months before conception. Routine prenatal maternal labs were unremarkable. The mother developed severe preeclampsia, complicated by pulmonary edema; thus, an emergency cesarean section was performed. The mother received prenatal steroids 4 hours prior to delivery.
At delivery, the baby appeared active without overt signs of hyperthyroidism, but she had evidence of respiratory distress. Her weight was 1380 grams $(60 \%)$, her length was $39 \mathrm{~cm}$ (59\%), and her head circumference was $28 \mathrm{~cm}(77 \%)$. Her initial chest radiograph was consistent with RDS; she was intubated and received 1 dose of surfactant and then she was extubated and placed on nCPAP. Apgar scores were 7 and 9 (at 1 and 5 minutes, resp.). She remained on CPAP for 1 day and then was transitioned to room air.

On DOL 2, she had several episodes of apnea and caffeine citrate was started. On DOL 3, she developed sinus tachycardia (HR $220 \mathrm{bpm}$ ). She was evaluated for hyperthyroidism. Thyroid function tests showed a high FT4 of $5.2 \mathrm{ng} / \mathrm{dL}$ (normal: $0.75-1.54 \mathrm{ng} / \mathrm{dL}$ ) and a suppressed TSH of $<0.05 \mathrm{mIU} / \mathrm{L}$ $(0.8-8.2 \mathrm{mIU} / \mathrm{L})$. She was started on atenolol $1 \mathrm{mg} / \mathrm{kg} / \mathrm{day}$ once daily and iodine (as Lugol's solution, $126.5 \mathrm{mg} / 5 \mathrm{~mL}$ ), 1 drop $(8 \mathrm{mg})$ every 8 hours, via a nasogastric tube.

On DOL 9, the infant was transferred to St. Christopher's Hospital for Children. Upon admission the vital signs were remarkable only for tachycardia (HR 180-210 bpm). The physical examination was normal. An echocardiogram 


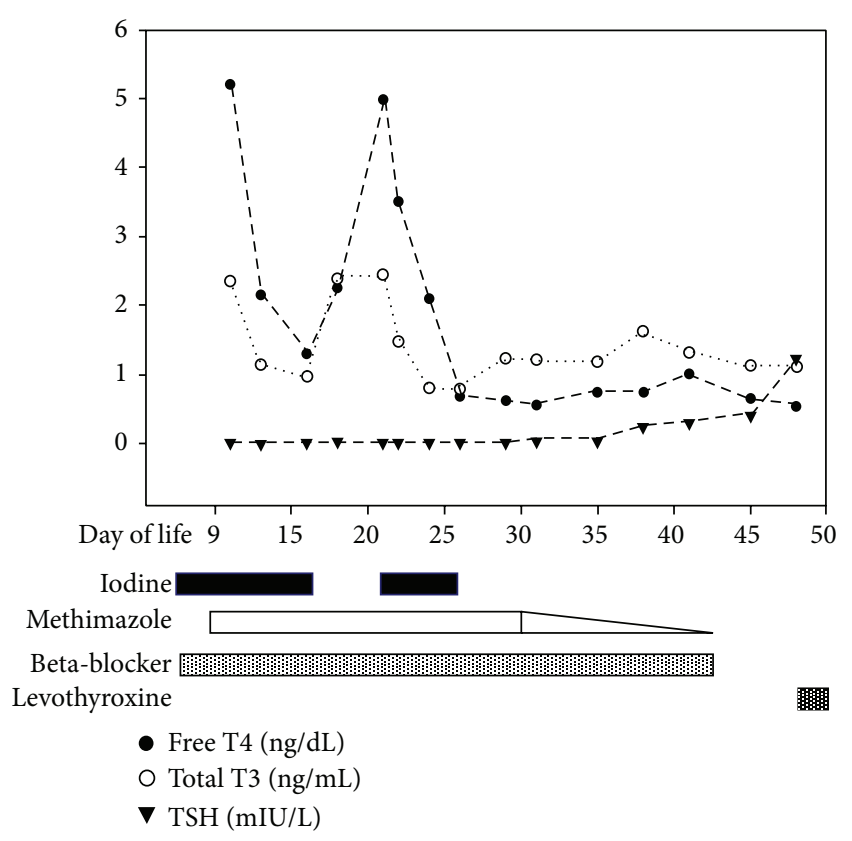

FIGURE 1: Free thyroxine (FT4) and thyroid stimulating hormone (TSH) levels and treatment course during hospitalization at our institution. Iodine, methimazole, beta-blocker, and levothyroxine are shown as bars at the end of the graph. The triangle at the end of methimazole bar represents the time that methimazole was started to be tapered.

demonstrated a small VSD but normal function. A HUS was normal.

On DOL 10, methimazole was started at $1 \mathrm{mg} / \mathrm{kg} /$ day in 3 divided doses, atenolol was discontinued, and propranolol was started at $1.5 \mathrm{mg} / \mathrm{kg} / \mathrm{day}$, in 3 divided doses, via a nasogastric tube. TSI and TBII were positive. During the next 5 days, thyroid hormone levels improved and the iodine solution was discontinued. A few days later, there was a rebound in the FT4 level, so the iodine was resumed and was able to be once again discontinued on DOL 25 (Figure 1).

Twenty days after the initiation of methimazole (DOL 30 ), she was noted to be neutropenic with an ANC of 990 cells $/ \mu \mathrm{L}$, reaching a nadir of 795 cells $/ \mu \mathrm{L}$ between DOL 33 and 39 (Figure 2). Methimazole was gradually tapered starting from day 30 and stopped on DOL 44 . The dose of methimazole was decreased by $20 \%$ every $2-3$ days during which there was frequent monitoring of the TFT and white blood cell counts. By DOL 40, the ANC started to recover. When the daily dose of methimazole reached a third of the initial dose, it was maintained for five days and then discontinued (see Table 1).

She was discharged home on DOL 49 (37-week corrected age), weighing 2310 grams. At discharge the infant had an ANC of 1793 cells $/ \mu \mathrm{L}$. The TFT was significant for a low FT4 level of $0.54 \mathrm{ng} / \mathrm{dL}$ but a normal TSH of $1.23 \mathrm{mIU} / \mathrm{L}$. Due to her hypothyroidism, she was started on levothyroxine on a dose of $25 \mathrm{mcg}$ PO daily. After discharge, on DOL 65, upon normalization of her TFT, levothyroxine was discontinued. Two weeks after the discontinuation of levothyroxine, repeat

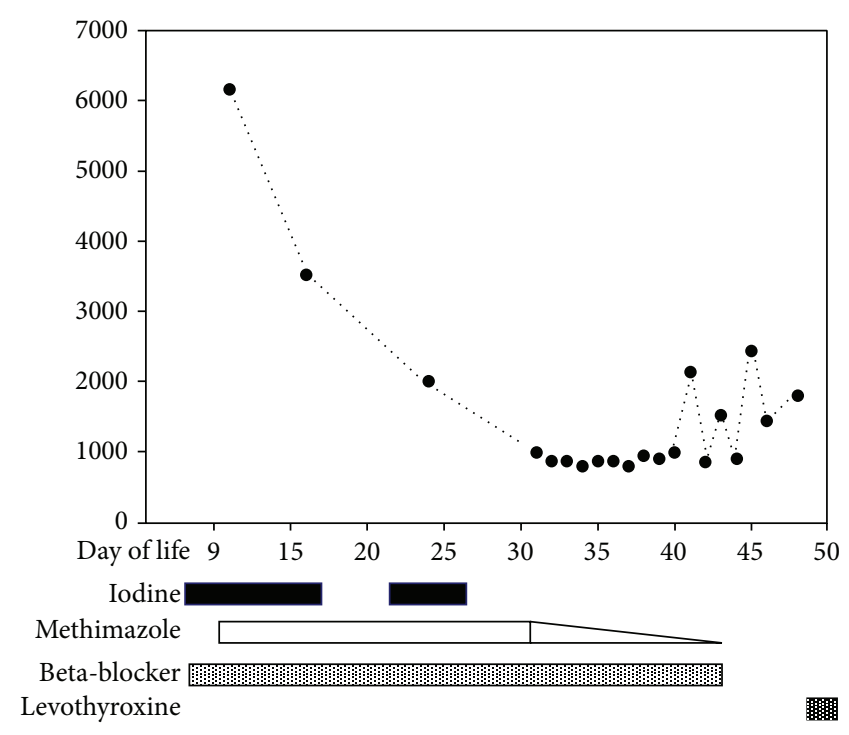

- ANC per $\mu \mathrm{L}$

FIGURE 2: The absolute neutrophil count (ANC) is shown. Neutropenia was noted after 20 days of methimazole use (DOL 30). Iodine, methimazole, beta-blocker, and levothyroxine are shown as bars at the end of the graph. The triangle at the end of methimazole bar represents the time it was tapered.

thyroid hormone levels were within normal limits. At her 2year follow-up by her pediatrician, the patient had normal growth, premature thelarche, a language barrier, and developmental delay based on Denver Developmental Screening. She was receiving early intervention for speech and physical therapy.

\section{Discussion}

This is a case of methimazole induced neutropenia in a preterm neonate with neonatal hyperthyroidism, secondary to maternal Graves' disease. Maternal Graves' disease is relatively uncommon with an estimated incidence of $0.4 \%-$ $1 \%$ of all pregnancies, but only $1-5 \%$ of newborns delivered to mothers with Graves' disease develop overt clinical signs and symptoms of hyperthyroidism $[1,2]$.

Methimazole and propylthiouracil (PTU) have been used as initial treatment of pediatric and neonatal Graves' disease. The mechanism of action of both drugs is to inhibit thyroid hormone synthesis by blocking thyroid peroxidase. This enzyme plays an important role in the iodination of the tyrosine residues in the thyroglobulin molecule and in the ultimate production of thyroxine and triiodothyronine. Both of these medications appear to be equally effective. Methimazole, though, is increasingly being used in the United States for the treatment of hyperthyroidism in children, because of the lower risk of hepatotoxicity compared to PTU [3]. The Federal Drug Administration has placed a black box warning against using PTU as a first line drug. PTU is still often used during the first trimester of pregnancy due to methimazole associated birth defects $[1,4]$. 
TABLE 1: Free T4, total T3, and TSH levels as well as white blood cell count and absolute neutrophil counts during hospitalization at our institution. Normal values for FT4: 0.75-1.54 (ng/dL), T3: 0.9-2.6 (ng/mL), and TSH: $0.5-6.5 \mathrm{mIU} / \mathrm{L}$.

\begin{tabular}{|c|c|c|c|c|c|}
\hline $\begin{array}{l}\text { Day of } \\
\text { life }\end{array}$ & $\begin{array}{l}\text { Free T4 } \\
(\mathrm{ng} / \mathrm{dL})\end{array}$ & $\begin{array}{l}\text { Total T3 } \\
\text { (ng/mL) }\end{array}$ & $\begin{array}{c}\text { TSH } \\
(\mathrm{mIU} / \mathrm{L})\end{array}$ & $\begin{array}{c}\text { WBCs } \\
(\text { Cells } / \mu \mathrm{L})\end{array}$ & $\begin{array}{c}\text { ANCs } \\
(\text { Cells } / \mu \mathrm{L})\end{array}$ \\
\hline 10 & 5.2 & 2.36 & 0.02 & 14000 & 6160 \\
\hline 12 & 2.16 & 1.15 & 0.01 & & \\
\hline 15 & 1.3 & 0.98 & 0.02 & 16700 & 3507 \\
\hline 17 & 2.26 & 2.39 & 0.03 & & \\
\hline 20 & 4.99 & 2.45 & 0.02 & & \\
\hline 21 & 3.5 & 1.48 & 0.02 & & \\
\hline 23 & 2.1 & 0.8 & 0.02 & 18200 & 2002 \\
\hline 25 & 0.7 & 0.79 & 0.02 & & \\
\hline 28 & 0.62 & 1.23 & 0.02 & & \\
\hline 30 & 0.57 & 1.21 & 0.04 & 16005 & 990 \\
\hline 31 & & & & 15200 & 870 \\
\hline 32 & & & & 17900 & 860 \\
\hline 33 & & & & 15900 & 795 \\
\hline 34 & 0.75 & 1.19 & 0.05 & 13000 & 870 \\
\hline 35 & & & & 15000 & 860 \\
\hline 36 & & & & 20000 & 795 \\
\hline 37 & 0.75 & 1.62 & 0.24 & 15700 & 942 \\
\hline 38 & & & & 15900 & 900 \\
\hline 39 & & & & 16500 & 990 \\
\hline 40 & 1.01 & 1.32 & 0.31 & 19400 & 2134 \\
\hline 41 & & & & 17100 & 855 \\
\hline 42 & & & & 16800 & 1512 \\
\hline 43 & & & & 12800 & 896 \\
\hline 44 & 0.66 & 1.13 & 0.42 & 14400 & 2440 \\
\hline 45 & & & & 12100 & 1444 \\
\hline 47 & 0.54 & 1.12 & 1.23 & 16300 & 1793 \\
\hline
\end{tabular}

Neutropenia is a serious, but rare, side effect of both methimazole and PTU. In adults, the estimated incidence of severe drug induced neutropenia is about $0.35 \%$ [5]. In the adult literature, most authors use the term agranulocytosis for severe cases of neutropenia when the absolute neutrophil count (ANC) is less than 500 cells $\mu \mathrm{L}$, accompanied by fever, sore throat, and signs of sepsis. The definition of antithyroid drug induced neutropenia is not established in neonates and, therefore, the incidence is unknown. Graves' disease might be a cause of a mild neutropenia that is usually self-limited [6]. In our case the neutrophil count reached a nadir level of 795 cells $/ \mu \mathrm{L}$.

Proposed mechanisms of methimazole induced neutropenia include production of autoimmune antibodies, hapten mediated autoimmunity, and a toxic effect on the bone marrow. Autoimmunity is thought to explain most cases of antithyroid drug induced neutropenia. This includes the presence of antineutrophil cytoplasmic antibodies (ANCA), a family of antibodies that are directed against neutrophil surface targets or cytoplasmic molecules (e.g., proteinase-3)
[7]. Irrespective of the proposed underlying pathophysiology described in the adult literature, the toxicity of the antithyroid drugs appears to be related to the total dose that is administered to the patient. Higher and prolonged dosing schedules appear to increase the risk of neutropenia. Takata et al. [8] showed that adults with Graves' disease who are treated with $30 \mathrm{mg}$ of methimazole daily developed agranulocytosis more frequently than those treated with $15 \mathrm{mg}$ daily. In adults who received methimazole, but not PTU, Cooper et al. [9] showed that this effect was dependent on the dose and also on the age of the patient. Specifically, patients older than 40 years old were more likely to develop neutropenia. Similar trends and relations have not been described in neonates treated with methimazole.

The timing of the neutropenia is variable. Data from adults show that usually this occurs within 90 days from the initiation of methimazole $[6,10,11]$. Neutropenia might occur as early as 6 days [12] or as late as 10 years after the initiation of the drug [13]. In our case, neutropenia appeared early in the course of methimazole ( 20 days after the initiation of treatment) and the neutrophil counts started to improve immediately after the initiation of the weaning of methimazole. This suggests that neutropenia may be dose related and it makes the theory of direct bone marrow toxicity unlikely for this patient.

The recovery time of the neutrophil counts after the discontinuation of methimazole is approximately 10 days [10]. Cooper [6] suggests that the antithyroid medications should be stopped if the granulocyte count is less than $1000 / \mu \mathrm{L}$, with close monitoring in those patients with counts more than 1000 cells $/ \mu \mathrm{L}$, but less than $1500 / \mu \mathrm{L}$. Although we did not stop the methimazole, despite the fall of the ANC to less than 1000 cells $/ \mu \mathrm{L}$, we did follow a weaning protocol. We noted that the neutrophil count started to recover only by decreasing the dose of methimazole (by $20 \%$ every $2-3$ days) and normalized by day of life 40 . Our patient remained asymptomatic after day of life 25 . Our observation that the neutrophil counts started to recover only when the dose of methimazole was decreased might be clinically relevant in neonates who develop neutropenia but remain hyperthyroid, despite maximal pharmacologic treatment. Reassuring in neonates who develop hyperthyroidism secondary to maternal Graves' disease is the knowledge that transplacentally acquired antibodies have a finite life span.

The management of neutropenia related to antithyroid medications in neonates is not established. Data from adults who have been treated with methimazole and who developed agranulocytosis show that stopping the medication is necessary for recovery [6]. The use of granulocyte colonystimulating factor (G-CSF) has been shown to decrease the duration of neutropenia and achieve faster recovery [14]. This effect seems to be attenuated in cases of severe agranulocytosis with suppression of the bone marrow [15].

Pregnancy induced hypertension and preeclampsia are common complications of maternal hyperthyroidism. Our patient was delivered at 31-week GA, due to severe maternal preeclampsia. Millar et al. [16] showed that mothers with uncontrolled hyperthyroidism are at increased risk of severe preeclampsia. In cases though of uncontrolled 
hyperthyroidism there is also increased risk of prematurity, intrauterine growth restriction, and placental abruption. Mass screening (during or after pregnancy) may be important to prevent the deleterious effects of uncontrolled hyperthyroidism. It has been suggested that screening should be focused specifically on infants born to mothers with a previously affected infant, infants born to mothers who have received ablative treatment with radioiodine, or infants born to mothers with elevated maternal thyrotropin receptor antibodies at delivery [17]. The level of thyrotropin receptor antibodies at delivery (e.g., from cord blood) can predict the possibility of developing symptomatic hyperthyroidism in a newborn and could be used as a screening tool [18].

Babies born to mothers who were hyperthyroid during embryogenesis are at risk of congenital anomalies [19]. The presence of high levels of thyroid hormones affects the developing neonatal brain via various mechanisms that involve alterations in the production of neurotransmitter synthesis and the release of inflammatory cytokines [20]. In an animal model of induced hyperthyroidism, treatment with T3 resulted in decrease of growth of the cerebrum and to lesser degree of the cerebellum. The reduced brain size was caused by a permanent reduction in the final brain cell number [21]. There are limited data on long term developmental outcome of infants exposed to high levels of thyroid hormones in fetal or neonatal period. Hollingsworth and Mabry [22] reported four cases of congenital Graves' disease who had an autosomal dominant history of thyrotoxicosis and a possible gene mutation in the TSH receptor. Three out of four patients had growth delays and all had developmental delays upon follow-up. Our patient had a normal growth pattern at 2 years of age with no evidence of craniosynostosis, but she had a language delay which could be attributed to her exposure to abnormal levels of maternal thyroid hormones but also to her prematurity or growing up in a bilingual environment. Daneman and Howard [23] found varying degrees of intellectual impairment in six out of eight patients with neonatal hyperthyroidism with intellectual quotients ranging from 75 to 85 . The six affected patients had craniosynostosis and all eight of them had normal physical growth.

Our patient presented with hyperthyroidism followed by transient hypothyroidism requiring treatment with levothyroxine. In a cohort of one preterm and three term neonates with overt hyperthyroidism, born to mothers with Graves' disease, Yael et al. [24] observed that FT4 peaked within the first 5 days of life, while TSH remained suppressed for up to three months. Central (pituitary) hypothyroidism following hyperthyroidism has been previously described in a preterm infant born to a mother with Graves' disease [25]. Kempers et al. [26] reported that all women with Graves' disease who gave birth to children with central congenital hypothyroidism were inadequately treated and that the incidence of central congenital hypothyroidism (due to prolonged suppression of the axis) secondary to maternal gestational hyperthyroidism was about $1: 35,000$. Since both hypothyroidism and hyperthyroidism are associated with adverse neurodevelopmental outcomes, more retrospective studies are needed to further evaluate and verify the neurocognitive development of patients with neonatal Graves' disease.

\section{Abbreviations}

ANC: Absolute neutrophil count

ANCA: Antineutrophil cytoplasmic antibodies

BPM: Beats per minute

DOL: Day of life

FT4: $\quad$ Free thyroxine

FDA: Federal Drug Administration

HR: Heart rate

HUS: Head ultrasound

nCPAP: Nasal continuous positive airway pressure

PTU: Propylthiouracil

RDS: Respiratory distress syndrome

T3: Total triiodothyronine

TBII: Thyrotropin-binding inhibitory immunoglobulin

TSH: Thyroid stimulating hormone

TSI: Thyroid stimulating immunoglobulin

TFT: Thyroid function test

VSD: Ventricular septal defect.

\section{Conflict of Interests}

The authors have no conflict of interests to disclose.

\section{Authors' Contribution}

Dr. Dimitrios Angelis cared for the patient, wrote the initial manuscript and revised drafts of the paper, and approved the final paper as submitted. Dr. Rita Ann Kubicky was the Pediatric Endocrinology Consultant who helped in the care for the patient, reviewed and revised the paper, and approved the final paper as submitted. Dr. Alan B. Zubrow was the attending physician who cared for the patient, reviewed and revised the paper, and approved the final paper as submitted.

\section{References}

[1] L. de Groot, M. Abalovich, E. K. Alexander et al., "Management of thyroid dysfunction during pregnancy and postpartum: an endocrine society clinical practice guideline," The Journal of Clinical Endocrinology \& Metabolism, vol. 97, no. 8, pp. 25432565, 2012.

[2] J. M. McKenzie and M. Zakarija, "Fetal and neonatal hyperthyroidism and hypothyroidism due to maternal TSH receptor antibodies," Thyroid, vol. 2, no. 2, pp. 155-159, 1992.

[3] S. A. Rivkees and D. R. Mattison, "Propylthiouracil (PTU) hepatoxicity in children and recommendations for discontinuation of use," International Journal of Pediatric Endocrinology, vol. 2009, no. 1, Article ID 132041, 2009.

[4] R. S. Bahn, H. S. Burch, D. S. Cooper et al., "The Role of Propylthiouracil in the Management of Graves' Disease in Adults: report of a meeting jointly sponsored by the American Thyroid Association and the Food and Drug Administration," Thyroid, vol. 19, no. 7, pp. 673-674, 2009.

[5] J. Tajiri and S. Noguchi, "Antithyroid drug-induced agranulocytosis: special reference to normal white blood cell count agranulocytosis," Thyroid, vol. 14, no. 6, pp. 459-462, 2004.

[6] D. S. Cooper, "Antithyroid drugs," The New England Journal of Medicine, vol. 352, no. 9, pp. 905-917, 2005. 
[7] T. Akamizu, S. Ozaki, H. Hiratani et al., "Drug-induced neutropenia associated with anti-neutrophil cytoplasmic antibodies (ANCA): possible involvement of complement in granulocyte cytotoxicity," Clinical and Experimental Immunology, vol. 127, no. 1, pp. 92-98, 2002.

[8] K. Takata, S. Kubota, S. Fukata et al., "Methimazole-induced agranulocytosis in patients with Graves' disease is more frequent with an initial dose of $30 \mathrm{mg}$ daily than with $15 \mathrm{mg}$ daily," Thyroid, vol. 19, no. 6, pp. 559-563, 2009.

[9] D. S. Cooper, D. Goldminz, A. A. Levin et al., "Agranulocytosis associated with antithyroid drugs. Effects of patient age and drug dose," Annals of Internal Medicine, vol. 98, no. 1, pp. 2629, 1983.

[10] F. Andersohn, C. Konzen, and E. Garbe, "Systematic review: agranulocytosis induced by nonchemotherapy drugs," Annals of Internal Medicine, vol. 146, no. 9, pp. 657-665, 2007.

[11] M. Meyer-Gessner, G. Benker, S. Lederbogen, T. Olbricht, and D. Reinwein, "Antithyroid drug_-induced agranulocytosis: clinical experience with ten patients treated at one institution and review of the literature," Journal of Endocrinological Investigation, vol. 17, no. 1, pp. 29-36, 1994.

[12] J. Yang, J. Zhong, L.-Z. Zhou, T. Hong, X.-H. Xiao, and G.-B. Wen, "Sudden onset agranulocytosis and hepatotoxicity after taking methimazole," Internal Medicine, vol. 51, no. 16, pp. 21892192, 2012.

[13] P. Mutharasan, W. Oatis, H. Kwaan, and M. Molitch, "Delayed anithyroid drug-induced agranulocytosis," Endocrine Practice, vol. 18, no. 4, pp. e69-e72, 2012.

[14] S. A. Rivkees, K. Stephenson, and C. Dinauer, "Adverse events associated with methimazole therapy of graves' disease in children," International Journal of Pediatric Endocrinology, vol. 2010, no. 1, Article ID 176970, 2010.

[15] J. Tajiri, S. Noguchi, S. Okamura et al., "Granulocyte colonystimulating factor treatment of antithyroid drug- induced granulocytopenia," Archives of Internal Medicine, vol. 153, no. 4, pp. 509-514, 1993.

[16] L. K. Millar, D. A. Wing, A. S. Leung, P. P. Koonings, M. N. Montoro, and J. H. Mestman, "Low birth weight and preeclampsia in pregnancies complicated by hyperthyroidism," Obstetrics and Gynecology, vol. 84, no. 6, pp. 946-949, 1994.

[17] Z. Nachum, Y. Rakover, E. Weiner, and E. Shalev, “Graves' disease in pregnancy: prospective evaluation of a selective invasive treatment protocol," The American Journal of Obstetrics and Gynecology, vol. 189, no. 1, pp. 159-165, 2003.

[18] D. Peleg, S. Cada, A. Peleg, and M. Ben-Ami, “The relationship between maternal serum thyroid-stimulating immunoglobulin and fetal and neonatal thyrotoxicosis," Obstetrics and Gynecology, vol. 99, no. 6, pp. 1040-1043, 2002.

[19] N. Momotani, K. Ito, N. Hamada, Y. Ban, Y. Nishikawa, and T. Mimura, "Maternal hyperthyroidism and congenital malformation in the offspring," Clinical Endocrinology, vol. 20, no. 6, pp. 695-700, 1984.

[20] Å. K. Rasmussen, "Cytokine actions on the thyroid gland," Danish Medical Bulletin, vol. 47, no. 2, pp. 94-114, 2000.

[21] R. Balázs, S. Kovács, W. A. Cocks, A. L. Johnson, and J. T. Eayrs, "Effect of thyroid hormone on the biochemical maturation of rat brain: postnatal cell formation," Brain Research, vol. 25, no. 3, pp. 555-570, 1971.

[22] D. R. Hollingsworth and C. C. Mabry, "Congenital graves disease. Four familial cases with long term follow up and perspective," American Journal of Diseases of Children, vol. 130, no. 2, pp. 148-155, 1976.
[23] D. Daneman and N. J. Howard, "Neonatal thyrotoxicosis: intellectual impairment and craniosynostosis in later years," Journal of Pediatrics, vol. 97, no. 2, pp. 257-259, 1980.

[24] L.-S. Yael, T.-H. Liran, B. Valentina, L.-G. Liat, and P.-H. Orit, "Follow-up of newborns of mothers with Graves' disease," Thyroid, vol. 24, no. 6, pp. 1032-1039, 2014.

[25] R. Higuchi, T. Kumagai, M. Kobayashi, T. Minami, H. Koyama, and Y. Ishii, "Short-term hyperthyroidism followed by transient pituitary hypothyroidism in a very low birth weight infant born to a mother with uncontrolled Graves' disease," Pediatrics, vol. 107, no. 4, article E57, 2001.

[26] M. J. E. Kempers, D. A. van Tijn, A. S. P. van Trotsenburg, J. J. M. de Vijlder, B. M. Wiedijk, and T. Vulsma, "Central congenital hypothyroidism due to gestational hyperthyroidism: detection where prevention failed," The Journal of Clinical Endocrinology \& Metabolism, vol. 88, no. 12, pp. 5851-5857, 2003. 


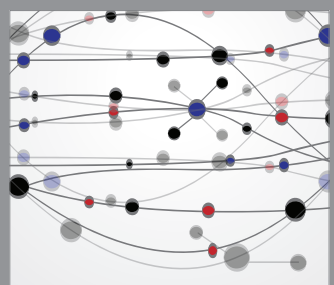

The Scientific World Journal
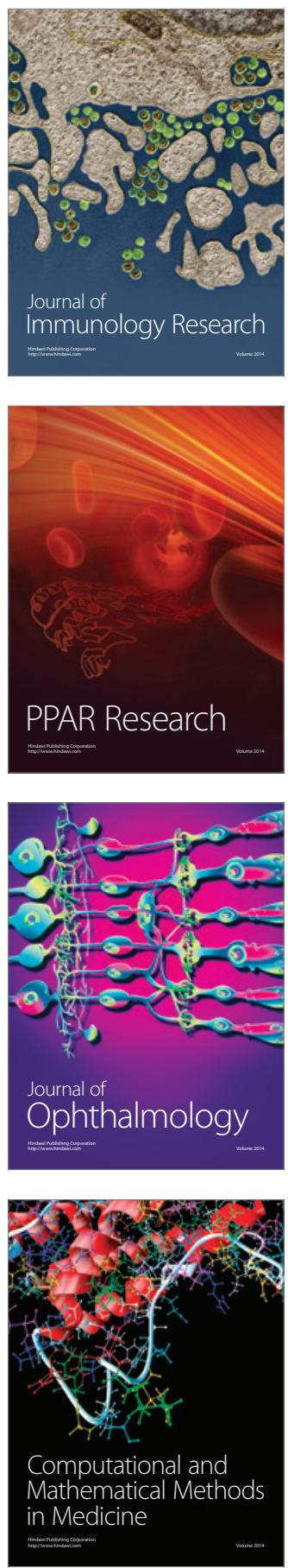

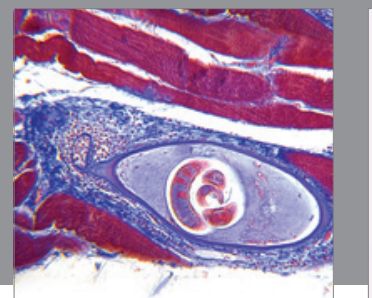

Gastroenterology

Research and Practice
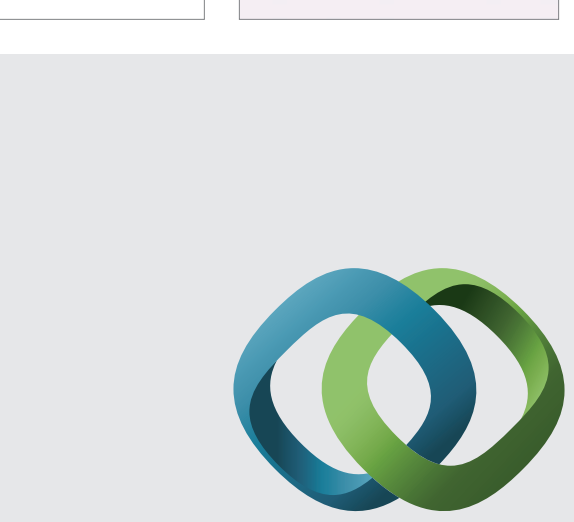

\section{Hindawi}

Submit your manuscripts at

http://www.hindawi.com
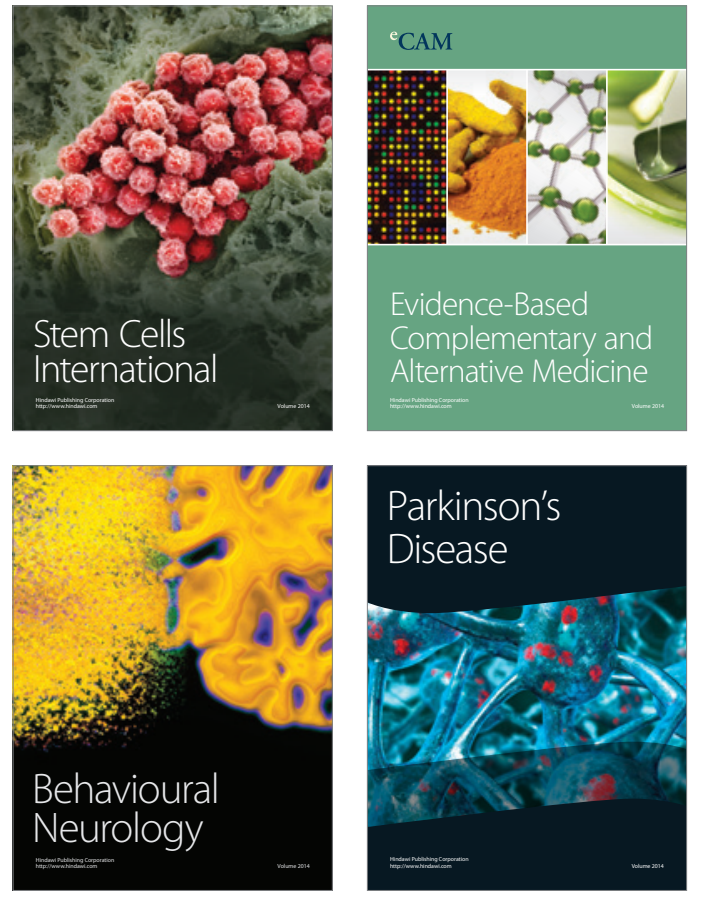
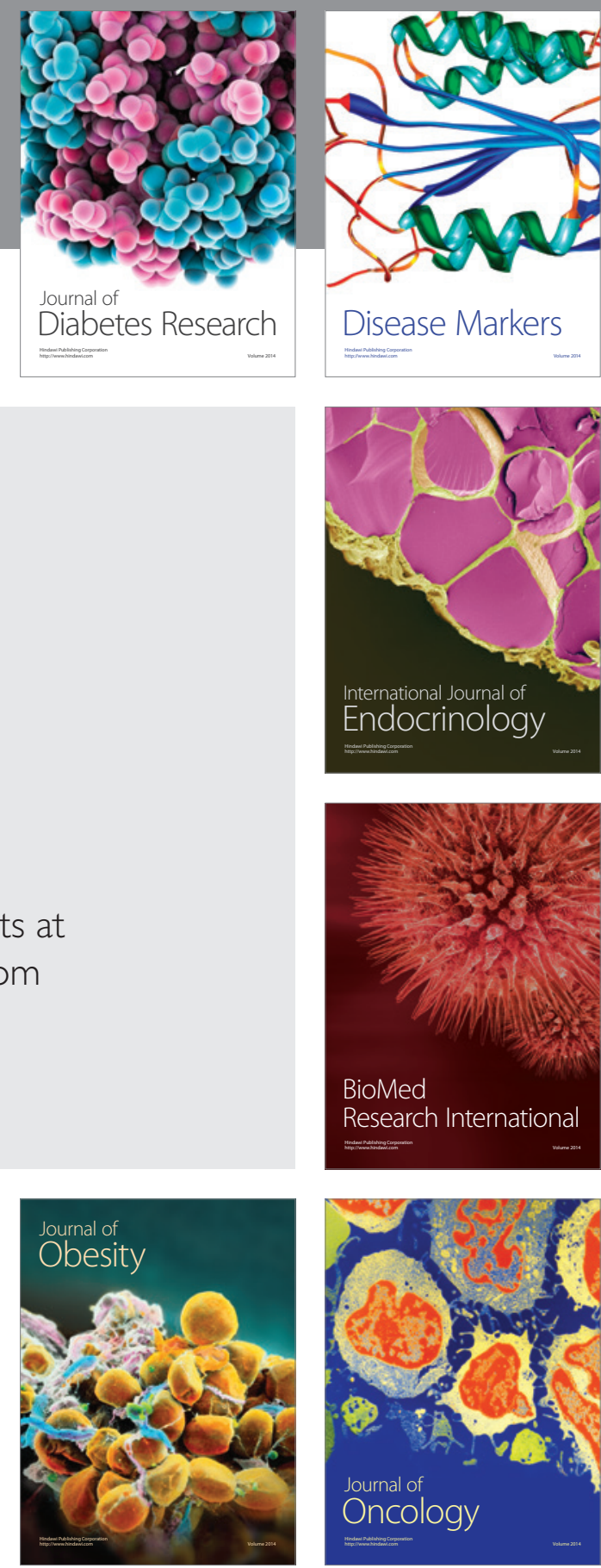

Disease Markers
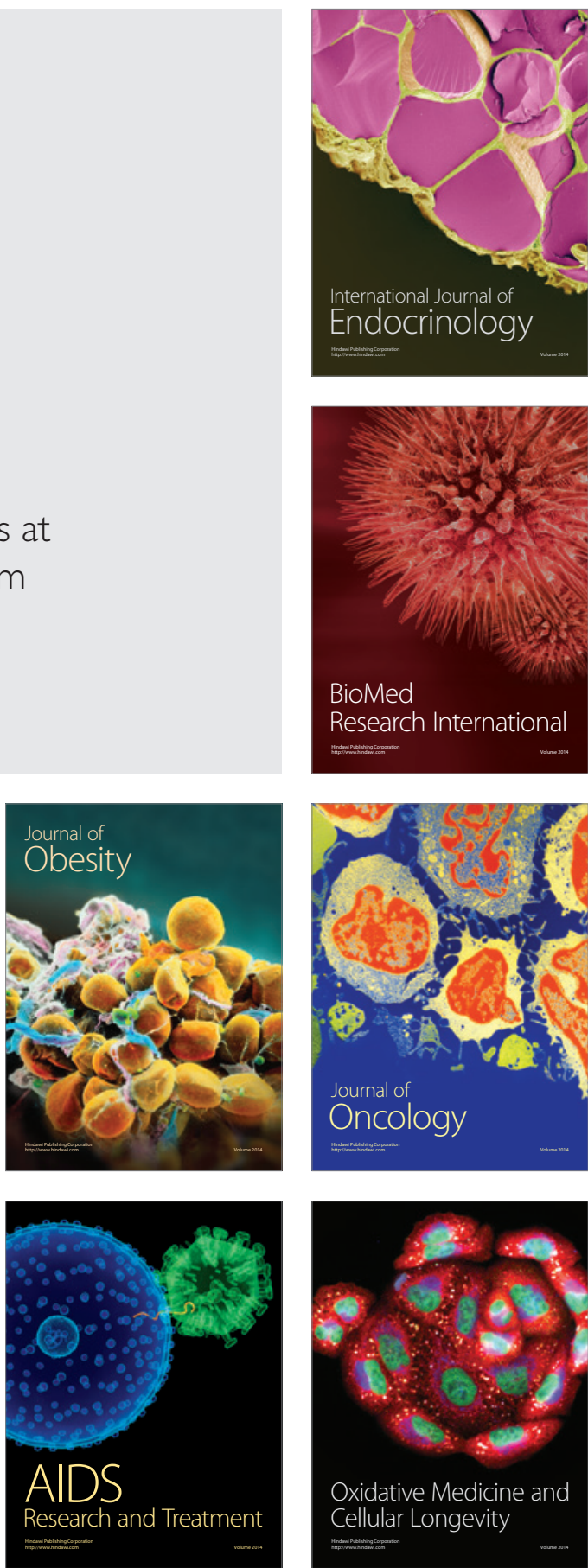